\title{
Ética del desarrollo en un mundo globalizado
}

\author{
EMILIO MARTÍNEZ NAVARRO* \\ Universidad de Murcia (España) \\ emimarti@um.es
}

\begin{abstract}
Resumen
En un mundo irreversiblemente globalizado, la ética del desarrollo señala los principales argumentos, conceptos y principios que pueden orientar las políticas de desarrollo en el interior de los países y también en las relaciones internacionales. Desde que nació en los años 60, la ética del desarrollo ha impulsado en gran medida el tránsito desde un concepto de desarrollo inicialmente muy pobre hasta el actual concepto complejo de desarrollo humano sostenible.
\end{abstract}

Palabras clave: ética del desarrollo, globalización, derechos humanos, desarrollo humano, desarrollo sostenible.

\section{Ethics of development in a globalized world}

\begin{abstract}
In an irreversibly globalized world, Development Ethics points out the main arguments, concepts and principles that can guide development policies within countries and also in international relations. Since it was born in the 1960s, Development Ethics has largely driven the transition from an initially very poor development concept to the present complex concept of sustainable buman development.
\end{abstract}

Key words: development ethics, globalization, human rights, human development, sustainable development.

\footnotetext{
* Doctor en Filosofía. Catedrático de Filosofía Moral y Política en la Universidad de Murcia. Forma parte del Grupo Interuniversitario de Investigación sobre Éticas Aplicadas y Democracia. Desde marzo de 2011 es Secretario de Daimon. Revista Internacional de Filosofía. Entre sus publicaciones cabe destacar los libros Ética profesional de los profesores (2010), Ética y fe cristiana en un mundo plural (2005), Ética para el desarrollo de los pueblos (2000), Solidaridad liberal: la propuesta de John Rawls (1999) y Ética (1996, junto con Adela Cortina).

Este estudio se inserta en el Proyecto de Investigación Científica y Desarrollo Tecnológico FFI2016-76753-C2-1-P, financiado por el Ministerio de Economía y Competitividad.
} 


\section{1. ¿EN QUÉ CONSISTE LA ÉTICA DEL DESARROLLO? ${ }^{1}$}

Entendemos aquí la Ética como una rama de la Filosofía que reflexiona sobre la moralidad, es decir, como "Filosofía moral". Ahora bien, la moralidad es un fenómeno muy complejo, y por ello la propia definición de la misma es objeto de controversia filosófica. Por ejemplo: para los filósofos utilitaristas la moralidad es cuestión de cálculo acerca de las posibles consecuencias de los comportamientos disponibles en un momento dado, bajo el imperativo de elegir entre ellos aquel comportamiento que sea más favorable para el mayor número de seres dotados de la capacidad de gozar y de sufrir. En cambio, para los filósofos de inspiración deontologista la moralidad no es sólo una cuestión de cálculo, aunque siempre hay que prever las consecuencias de los posibles cursos de acción, sino que hay límites a dicho cálculo en no dañar inmerecidamente a las personas, que son los únicos seres dotados de dignidad (no precio), ni siquiera en el caso hipotético de que el daño inmerecido infligido a una sola persona pudiera redundar en beneficio de la mayoría de seres capaces de sufrir.

Así pues, la Ética es una disciplina normativa, puesto que no describe lo que ocurre de hecho en el mundo, sino que trata de orientar indirectamente la acción humana argumentando sobre la mejor manera de entender la moralidad (Cortina \& Martínez, 1996). De modo que, según se entienda la moralidad de una manera o de otra, los principios y las normas que han de orientar el comportamiento pueden ser diferentes en algunos casos, aunque en la mayor parte de ellos es muy probable que dos éticas diferentes recomienden el mismo comportamiento.

Desde mediados del siglo XX ha aparecido un tercer tipo de saber ético, el de las llamadas "éticas aplicadas", que básicamente consiste en orientar el comportamiento humano en un ámbito concreto de las actividades sociales, como pueden ser las actividades económicas (Ética de la Economía y de la Empresa), las sanitarias (Bioética), las del ámbito político (Ética de la Política y la Administración Pública), las de las profesiones (Ética profesional de cada profesión), etc. Cada ética aplicada se construye de un modo interdisciplinar, con participación de filósofos, de científicos y de simples ciudadanos afectados por la actividad de que se trate (por ejemplo, los pacientes en la medicina, o los consumidores en la economía). La Ética del Desarrollo es una de estas éticas aplicadas, y como su nombre 1 Una versión previa de este trabajo fue publicada con el título "Ética del desarrollo:
superar la injusticia global" en Román \& De Castro (2013: 38-53). 
indica, pretende orientar los comportamientos de las personas involucradas en los asuntos del desarrollo de los países que conforman nuestro mundo (Martínez Navarro, 2000).

El término "desarrollo", empezó a ser aplicado a países y regiones del mundo a partir de finales de la Segunda Guerra Mundial, momento en el que algunos dirigentes políticos comenzaron a distinguir entre países "desarrollados" y "subdesarrollados", y momento también en el que los documentos fundacionales de las Naciones Unidas y de las instituciones financieras de Bretton Woods (es decir, el Fondo Monetario Internacional y el Banco Mundial), introdujeron el término "desarrollo" para referirse a la situación óptima deseable para cualquier país. Así, por ejemplo, el nombre original del Banco Mundial, fundado en 1944, fue el de International Bank for Reconstruction and Development, este nombre sugiere que, tras la tremenda destrucción llevada a cabo por la guerra, el objetivo del banco no podía ser otro que "la reconstrucción y el desarrollo" de los países afectados por el conflicto bélico que estaba a punto de finalizar. Ahora bien, una vez logrados, en términos generales, los objetivos de reconstrucción, el Banco asumió como misión principal la de reducir la pobreza, de manera que, en el lenguaje de la segunda mitad del siglo XX, las expresiones "ayuda para la reducción o superación de la pobreza" y "ayuda para el desarrollo" llegaron a ser sinónimas. En términos generales, por tanto, podemos afirmar que, en su origen histórico, el término "desarrollo" se refería a la situación que logra un país cuando consigue salir de la pobreza. Probablemente, quienes difundieron el término operaban con la idea de que, si los pueblos del mundo alcanzan de veras el desarrollo, entonces las guerras tenderán a desaparecer (Cortina, 2007; Conill, 2007).

Sin embargo, estos buenos deseos se vieron enfrentados desde muy pronto con los problemas de la guerra fría, y en ese nuevo contexto se utilizó la idea del desarrollo como un elemento más de la rivalidad entre los dos grandes bloques políticos de la época. De este modo quedó pervertida y manipulada la propia noción de desarrollo, porque la finalidad ética primordial de los procesos de desarrollo - la superación de la pobreza-, quedó inmediatamente postergada en relación con una meta propagandística propuesta por cada una de las dos superpotencias en sus respectivas áreas de influencia: la meta de "salir del subdesarrollo" alineándose con el bando correcto. En aquel contexto es el que nace la Ética del Desarrollo: esta disciplina nace en los años sesenta del siglo XX como un conjunto de reflexiones críticas y de propuestas de cambio de rumbo en torno a los modelos de "desarrollo" que comenzaron a aplicarse tras la Segunda Guerra Mundial. Los primeros autores que publicaron trabajos de Ética del Desarrollo fueron el francés Louis Joseph Lebret (1961) y el estadounidense Denis Goulet (1965). La principal denuncia que hicieron 
estos pioneros de la Ética del Desarrollo se podría resumir en los siguientes puntos:

- Se tiende a identificar el desarrollo de un país como un asunto exclusivamente económico, medible en términos del incremento del PIB o de la renta por habitante, sin atender a otros aspectos que deberían ser tenidos en cuenta, como la equidad en la distribución de la riqueza y la satisfacción de las necesidades básicas de la población.

- Se utiliza un concepto de desarrollo como equivalente a industrialización, modernización (entendida como abandono de formas de vida tradicionales) y, en general, adopción de modos de producción, de propiedad y de consumo que son típicos de Occidente, ignorando las posibilidades de otros posibles modelos de desarrollo que podrían ser diseñados e implementados a partir de las propias tradiciones de cada país.

El Centro Economie et Humanisme fue fundado en Francia en 1941 por Louis Joseph Lebret y desde el inicio de sus múltiples actividades académicas y culturales se afianzó como una referencia internacional en iniciativas destinadas a recomponer una adecuada relación entre ética y economía, incluyendo las cuestiones de ética del desarrollo. Muchos de los trabajos llevados a cabo por este grupo de intelectuales católicos influyeron decisivamente en los contenidos de la encíclica de Pablo VI (1967) conocida como Populorum progressio, cuyo título completo es Sobre la necesidad de promover el desarrollo de los pueblos. Este documento ya apuntaba en gran medida lo que posteriormente se ha llamado desarrollo bumano. Los ejes fundamentales del mismo se expresan allí del siguiente modo:

Verse libres de la miseria, hallar con más seguridad la propia subsistencia, la salud, una ocupación estable; participar todavía más en las responsabilidades, fuera de toda opresión y al abrigo de situaciones que ofenden su dignidad de hombres; ser más instruidos; en una palabra, hacer, conocer y tener más para ser más; tal es la aspiración de los hombres de hoy. $Y$, sin embargo, gran numero de ellos se ve condenado a vivir en condiciones que bacen ilusorio este legitimo deseo. Por otra parte, los pueblos llegados recientemente a la independencia nacional sienten la necesidad de añadir a esta libertad politica un crecimiento autónomo y digno, social no menos que económico, a fin de asegurar a sus ciudadanos su pleno desarrollo bumano y ocupar el puesto que les corresponde en el concierto de las naciones (Pablo VI, 1967, \6).

A partir de ese impulso inicial, y a lo largo de las últimas décadas, una gran cantidad de académicos de diversas especialidades y desde diversos continentes, a menudo en colaboración con activistas del desarrollo y con 
líderes de comunidades en desarrollo, han dado lugar a una amplia reflexión sobre esta disciplina. Se ha creado una asociación específica para la promoción de la Ética del Desarrollo (International Development Ethics Asociation, $\mathrm{IDEA}^{2}$ ) y se organizan regularmente congresos, talleres de trabajo y seminarios.

\section{2. ¿EN QUÉ CONSISTE UN DESARROLLO ÉTICO?}

El desarrollo de un país puede ser una meta éticamente deseable, pero es preciso no caer en la trampa de entenderlo como mero crecimiento económico o incremento del Producto Interno Bruto (PIB). Por ejemplo, un país podría incrementar durante unos años su PIB a costa de talar sus bosques y vender la madera en el mercado internacional, pero nadie podría aceptar sensatamente que semejante proceso de destrucción de sus recursos forestales se pueda considerar como verdadero desarrollo. Hay una "racionalidad ética" que va más allá de otros tipos de racionalidad económica, y en especial más allá de la racionalidad economicista y cortoplacista del supuesto homo economicus. Sobre este punto la aportación de Goulet (1995) es relevante: La racionalidad ética puede ser distinguida de la racionalidad técnica y de la racionalidad política. La racionalidad ética tiene como meta la promoción de ciertos valores por sí mismos, mientras que la técnica tiene como objetivo aplicar el conocimiento científico a la resolución eficiente de problemas concretos, y la racionalidad política se centra en asegurar la supervivencia de ciertas instituciones y el mantenimiento de ciertas posiciones de poder. La racionalidad ética se caracteriza por su pretensión de establecer prioridades en función de ciertos valores; este enfoque ético es el único que puede realizar juicios acerca de lo bueno y lo malo, de lo correcto y de lo incorrecto, de lo justo y lo injusto. Sin embargo, según Goulet no sería acertado que la racionalidad ética sea erigida como dominante frente a las otras dos:

[...] los problemas surgen porque cada racionalidad tiende a tratar a las demás de modo reduccionista, intentando imponer su punto de vista particular sobre los fines y procedimientos, durante todo el proceso de toma de decisiones. Las decisiones resultantes pueden ser técnicamente correctas pero disparatadas políticamente, o repulsivas éticamente; en otros casos pueden ser éticamente válidas pero técnicamente ineficientes o políticamente imposibles. Las tres racionalidades deben operar mejor según un modelo de interacción circular que vertical. Ésta es la única via para evitar el reduccionismo y la adopción de malas decisiones garantizadas (Goulet, 1995b: 13s).

2 Esta asociación académica fue fundada en San José de Costa Rica en 1987 (http://www.development-ethics.org). 
El modelo circular al que se refiere Goulet en esta cita es el de tener en cuenta, al mismo tiempo, las exigencias de las tres racionalidades, evitando en lo posible los intentos de que una de las tres se convierta en la única relevante para tomar las decisiones. Desde este punto de vista, las tareas y proyectos de desarrollo deberían ser, al mismo tiempo, técnicamente realizables, políticamente viables y éticamente deseables.

En este sentido, David Crocker, ha señalado que entre las fuentes de la Ética del Desarrollo hay que contar con las reflexiones de "Gandhi en India, Raúl Prébish en América Latina y Franz Fanon en África, que criticaron el desarrollo económico colonial y/o ortodoxo" (Crocker, 2003: 76). Las aportaciones de economistas como Gunnar Myrdal y Benjamin Higgins también contribuyeron a poner de manifiesto que el concepto de desarrollo que se ha venido manejando durante décadas es manifiestamente unilateral, insuficiente y erróneo, al confundirse con la obsesión por un crecimiento económico rápido, desequitativo y a cualquier coste humano y cultural. Frente a ese concepto de supuesto desarrollo, la Ética del Desarrollo de Goulet mantuvo que "el desarrollo es un concepto total que apunta al progreso hacia una economía humana caracterizada por la progresión de todos los hombres en todas sus dimensiones" (Goulet, 1965: 13).

\section{3. ¿TENEMOS LA OBLIGACIÓN ÉTICA DE AYUDAR A QUIENES PADECEN EL SUBDESARROLLO?}

El siguiente paso en la profundización ética del concepto de desarrollo vino de la mano de dos polémicas surgidas en los años setenta: Una en torno a las responsabilidades del Primer Mundo respecto al hambre y la miseria que padecen millones de personas en el mundo subdesarrollado, y la otra en torno a las prioridades que deberían adoptar las políticas económicas para ayudar eficazmente a esas personas a superar la miseria.

En el contexto de la primera polémica destacó la aportación de Peter Singer, que en su Practical Ethics de 1979 criticaba agriamente la cínica pretensión de cierta corriente de pensamiento, encabezada por Garrett Hardin, de dejar morir de hambre y de enfermedades curables a los pobres del mundo como única salida para la supervivencia de la humanidad, puesto que, supuestamente, si los que estamos libres de miseria ayudásemos a los empobrecidos, el resultado sería el empobrecimiento generalizado y la muerte de todos ${ }^{3}$. Aunque este "argumento" para desentenderse de la

\footnotetext{
3 Este planteamiento es conocido como "ética del bote salvavidas", al haber sido expuesta con esa metáfora - si dejamos que los pobres suban a nuestra barca, nos hundiremos todos- por Garret Hardin en un artículo titulado "Living in a Lifeboat" que se publicó por primera vez en la revista Bioscience de octubre de 1974. El dilema planteado
} 
suerte de casi un tercio de la humanidad no ha encontrado nuevos respaldos explícitos en el ámbito académico, lo cierto es que la dinámica de incumplimiento de los compromisos de cooperación para el desarrollo de los países ricos trasluce de hecho una hipocresía, un doble discurso moral por parte de estos países. Por una parte, los líderes de los países ricos parecen haber aceptado la recomendación aprobada por la Asamblea General de la ONU de 1974 sobre la necesidad de donar al menos el 0,7\% de su PIB para superar esas situaciones de pobreza extrema, mientras que varias décadas más tarde, el porcentaje promedio de ayuda real no está llegando ni al 0,3\% de la extraordinaria cantidad de riqueza que se genera en el mundo y que resulta acaparada por esos mismos países ricos.

Desde el punto de vista de la Ética del desarrollo, podemos contemplar las aportaciones de Singer (2000), de Pogge (2002), de Schweickart (2002) y de García Delgado y Molina (2006) en torno a las responsabilidades éticas que corresponden a los países ricos y a las personas acomodadas respecto a la situación de pobreza extrema de millones de personas, como valiosos elementos de crítica al concepto de desarrollo realmente imperante. Estos autores han puesto mucho énfasis en la necesidad urgente de que cese la hipocresía y las malas prácticas de gobiernos y organizaciones mundiales —especialmente la OMC — en sus relaciones con los países empobrecidos. Ejemplos de este tipo de malas prácticas serían: a) reconocer a gobiernos golpistas y corruptos como legitimados para vender los recursos naturales del país que controlan militarmente y endeudar al gobierno con préstamos que generalmente no benefician a la población en absoluto; b) amparar a dichos gobernantes en sus pretensiones de disponer de cuentas bancarias en "paraísos fiscales" que son escandalosamente tolerados por la comunidad internacional; c) tolerar e incluso fomentar que se mantengan en muchos países pobres unas amplias posibilidades de explotación laboral, de contaminación ambiental y de múltiples violaciones de los Derechos Humanos en nombre de la libertad de mercado, mientras que al mismo tiempo se mantienen políticas proteccionistas ante los productos procedentes de los países pobres; d) no donar a los países pobres una mínima parte de nuestra riqueza que podría ser suficiente para acabar con la pobreza extrema (Pogge, 2002: 21).

por Hardin es engañoso, porque, siguiendo con su metáfora, la realidad no es que los ricos vamos en un bote abarrotado donde no cabe más gente, sino que más bien navegamos en un lujoso buque de crucero en el que hay también pobres que malviven trabajando duramente para los ricos, y en el que habría sitio para todos los náufragos que nadan alrededor con tal que esos ricos accediesen a compartir una parte de sus riquezas. 
Por su parte, García Delgado y Molina (2006) argumentan certeramente que: 1) es urgente modificar las asimetrías en las transacciones existentes entre países desarrollados y en desarrollo, tanto en lo financiero, como en lo comercial, ambiental y tecnológico; 2) es preciso abandonar el paradigma neoliberal del "Estado mínimo", cuyas consecuencias en términos de desarrollo humano sostenible han sido desastrosas, y sustituirlo por un nuevo paradigma de Estado responsable que vele por la redistribución del ingreso, la preservación de los bienes públicos, la promoción de la competitividad con cohesión social y la generación de empleo digno para todos. Algunos de estos planteamientos aparecen, si bien de un modo demasiado tímido y contradictorio, en los nuevos Objetivos del Desarrollo Sostenible (ONU 2015) que han sido aprobados como Agenda 2030 de Naciones Unidas.

\section{NECESIDADES BÁSICAS Y SOSTENIBILIDAD MEDIOAMBIENTAL}

Con respecto a la otra polémica apuntada, referente a las prioridades que deberían adoptar las políticas económicas en vistas al desarrollo de los pueblos, en los años setenta aparecen las aportaciones de Galtung (1978), Max-Neef (1993), Streeten (1981) y otros muchos, que señalan con acierto la imperiosa necesidad de poner en primer lugar la satisfacción de las necesidades humanas básicas como el objetivo principal que debería orientar las políticas de desarrollo y de ayuda al desarrollo. Este tipo de aportaciones fueron despejando el camino para un nuevo concepto del desarrollo que aparece a comienzos de los noventa: la noción de desarrollo bumano. Pero antes de entrar en detalles sobre esta noción, hemos de dar cuenta de la novedad introducida en las cuestiones del desarrollo a partir de finales de los ochenta: el desarrollo sostenible o desarrollo sustentable.

En efecto, a partir de la publicación en 1987 del informe elaborado por la Comisión Mundial para el Medio Ambiente y el Desarrollo, presidida por la doctora Brundtland, la polémica ética más importante estuvo centrada en las posibilidades e imperativos que plantea la preocupante situación ecológica que afecta a todo el planeta. El informe mostró claramente que el modelo de desarrollo imperante hasta ese momento es insostenible. El desarrollo sostenible quedó definido como aquel tipo de desarrollo que satisface las necesidades de la generación presente sin comprometer la capacidad de las generaciones futuras para satisfacer sus propias necesidades. En el final del documento, la Comisión afirma que

[...] las cuestiones que hemos planteado en el presente informe tienen inevitablemente una importancia de gran alcance para la calidad de vida en la Tierra - en realidad para la vida misma-. Hemos procurado demostrar cómo la supervivencia y el bienestar humanos 
pueden depender del éxito del empeño por hacer que el desarrollo sostenible pase a ser una ética mundial (Comisión, 1988: 363).

Desde el punto de vista de la Ética del desarrollo, las cuestiones relacionadas con el cuidado del medio ambiente pasaron al primer plano de estudio y debate, con aportaciones de un gran número de teóricos que han insistido en la posibilidad de hacer compatible la sostenibilidad medioambiental —en su doble faceta de preservación y de reparación de daños al medio ambiente- con el desarrollo bumano sin exclusiones (Goulet, 1995a; Riechmann, 1995; Martínez Navarro, 2000). El argumento central es que no será posible la sostenibilidad si no va acompañada del desarrollo humano. Esto se comprenderá más fácilmente al examinar a continuación las implicaciones éticas de la noción de desarrollo humano.

\section{EL DESARROLLO HUMANO COMO CLAVE ÉTICA DEL DESARROLLO}

El concepto de desarrollo de los países como desarrollo bumano ha sido definido como el proceso que conduce a la ampliación de las opciones y capacidades de las personas, que se concreta en: 1) una mejora de la esperanza de vida (cuyos principales componentes son la salud y la seguridad ciudadana), 2) la educación (medida en términos de alfabetización y escolarización) y 3) el acceso a los recursos necesarios para un nivel de vida digno (medido en renta per capita en paridad de poder adquisitivo).

Este enfoque del desarrollo ha tenido un impulso muy importante por parte de los autores del Informe sobre el Desarrollo Humano que anualmente publica el Programa de las Naciones Unidas para el Desarrollo (PNUD) desde 1990. Parece haber un consenso bastante generalizado en cuanto a la importancia de la aportación del economista indio Amartya Sen en el cambio de paradigma que supone la aparición de este concepto de desarrollo bumano (Griffin, 2001), que ha llamado a su propuesta desarrollo como libertad después de haber trabajado durante muchos años en la cuestión de las relaciones entre ética y economía.

La idea principal de Sen es que el desarrollo no es tanto una cuestión de aumento de la renta o la riqueza cuanto una progresiva ampliación de las capacidades humanas que permita a las personas gozar de libertad suficiente para llevar a cabo aquellos proyectos de vida que valoran (Sen 1999) ${ }^{4}$. Veamos resumidamente algunas de las tesis de Sen que han sentado las bases teóricas del concepto de desarrollo humano:

\footnotetext{
$4 \quad$ La aportación de Sen a las disciplinas que trabajan en el desarrollo, incluida la Ética del Desarrollo, es ampliamente reconocida y ha dado lugar a nuevas iniciativas académicas y cívicas que utilizan el enfoque de las capacidades como referencia central, como
} 
- En líneas generales son positivas las conquistas de los últimos dos siglos en cuanto al desarrollo económico y la extensión de la democracia liberal, así como el discurso en torno a los Derechos Humanos y el logro de una mayor esperanza de vida al nacer; al mismo tiempo, es lamentable e indignante la situación de miseria, la opresión y el deterioro medioambiental que se manifiestan en los países empobrecidos.

- Para superar esas lacras se precisa, entre otras cosas, una nueva concepción del desarrollo, que proponga como meta prioritaria la expansión de las libertades reales de todas las personas.

- Es preciso contar con la participación activa — con la agenciade todas y cada una de las personas que aspiran al desarrollo.

- El desarrollo es fruto de un proceso integrado en el que intervienen actividades económicas, sociales y políticas en una profunda interconexión.

- La expansión de las libertades depende de una multitud de factores como la educación, la sanidad, los derechos políticos y el acceso a los debates públicos, y todo ello es en gran medida independiente de las tasas de crecimiento económico.

- El desarrollo se opone frontalmente a las hambrunas, a la desnutrición actual de millones de personas, a la falta de acceso a los cuidados de salud, a la falta de acceso al agua potable y al saneamiento, a la falta de una educación básica para todos los niños y las niñas, a la falta de empleo o de algún tipo de seguridad económica, a la falta de un trato igualitario a las mujeres ${ }^{5}$ que permita a éstas disfrutar de las libertades de que gozan los varones, a la falta de condiciones sociales y económicas para alcanzar cierta longevidad que hoy es viable, y a la falta de libertades democráticas (incluyendo muy especialmente la libertad de expresión, la libertad de prensa y la privacidad en las comunicaciones).

- El enfoque del desarrollo como libertad no implica un único modelo de desarrollo para todos los lugares del mundo o para todos los escenarios posibles, puesto que las libertades son diversas y el modo de ordenarlas en un sistema coherente es múltiple.

- En contra de lo que se ha dicho a menudo, las medidas de desarrollo bumano no son un lujo que sólo pueden permitirse los países que ya

\footnotetext{
la Human Development and Capability Association (http://www.capabilityapproach.com).

Existe una abundante bibliografía sobre la necesidad de aprovechar los avances obtenidos en los estudios sobre el género en las tareas de desarrollo de los pueblos. Véase, por ejemplo, López y Alcalde (1999).
} 
son ricos, puesto que la mayor parte de los países que se han desarrollado comenzaron por dar prioridad a la educación, a los servicios de salud y en general a la atención para promover las capacidades básicas de las personas, y ello ha sido un factor decisivo en la propia dinámica del desarrollo económico.

- El sistema democrático, en sentido amplio, constituye un elemento esencial del proceso de desarrollo. Y ello por tres razones: 1) su importancia directa en cuanto expresión de capacidades básicas como la participación política y social; 2) su papel instrumental en la mejora de las posibilidades de los individuos para expresar y defender sus demandas de atención política (incluidas sus exigencias económicas) y 3) su papel constructivo en la conceptualización de las "necesidades" (puesto que las necesidades se concretan siempre en el contexto social). A ello hay que añadir el papel permisivo de las libertades políticas: permiten y fomentan la discusión pública. Esta discusión puede prevenir muchos desastres económicos, aunque su utilidad concreta dependerá en buena medida de las prioridades de los ciudadanos y del uso que hagan de los medios políticos a su alcance.

- En los procesos de desarrollo es muy relevante centrar la atención en la agencia de las mujeres, esto es, su protagonismo activo, tanto por el bienestar de las mujeres mismas como por su repercusión en otros campos como la supervivencia de los niños y la reducción de las tasas de fecundidad. La agencia de las mujeres es decisiva en tareas económicas, políticas y sociales de diverso tipo. El reconocimiento del liderazgo de las mujeres es acaso lo más urgente que hay que hacer en la economía política del desarrollo.

- En cuanto al crecimiento demográfico, aunque Sen cree que a menudo se exagera la incidencia negativa de este factor, también considera que hay que reducir las tasas de fecundidad de la mayoría de los países en desarrollo. Pero la vía que se ha mostrado más adecuada para ello no es la imposición coercitiva y la manipulación, sino las medidas que aumentan la libertad de las mujeres (a través de la educación, el empleo, el acceso a los cuidados de salud, etc.) y la responsabilidad de las familias en la planificación voluntaria.

- Otra cuestión controvertida es la de la supuesta oposición entre los valores que sustentan las libertades y los valores autóctonos de Asia, África u otras regiones del mundo. A juicio de Sen, ni en oriente ni en occidente ha habido nunca una homogeneidad de valores autóctonos, $y$ lo mismo que ha habido posiciones autoritarias en la historia de occidente, ha habido también posiciones no autoritarias en la historia de 
oriente. En los procesos de desarrollo no debe prestarse atención a generalizaciones infundadas que pretenden asociar el autoritarismo con los "verdaderos valores locales" y de ese modo encumbrar a dirigentes sin escrúpulos que adoptan una actitud represiva con respecto a los disidentes en la propia cultura local.

- También se ha dicho que no es posible programar racionalmente un proceso de desarrollo social. Para ello se han esgrimido distintas razones, pero Sen las refuta con acierto e insiste en que no puede haber verdadero desarrollo sin una preocupación global por el proceso de aumento de las libertades individuales acompañado de un compromiso social de contribuir a llevarlo a cabo.

- Hay dos grandes modelos del proceso que conduce al desarrollo de los pueblos: "BLAST" (acrónimo de blood, sweat and tears, un modelo de desarrollo que exige "sangre, sudor y lágrimas") y "GALA" (acrónimo de getting by, with a little assistance, un modelo de desarrollo alternativo al anterior, bajo el lema "yendo juntos, con un poco de ayuda"). Este último es claramente preferible, tanto desde el punto de vista ético como también desde el punto de vista meramente económico, porque los partidarios del modelo BLAST tienden al olvidar que el apoyo mutuo y la cooperación proporcionan entornos de confianza y promoción personal que no sólo son deseables por sí mismos, sino que generan una mayor productividad a medio y largo plazo.

\section{6. ¿QUUE nOS APORTA LA ÉTICA DEL DESARROLLO?}

Para finalizar, podemos resumir la aportación de la Ética del Desarrollo en la idea principal que a mi juicio constituye el impulso y el sentido de la misma: es preciso superar un concepto unilateral e injusto de desarrollo, que nos ha llevado al escándalo de que sigan muriendo todos los días miles de personas víctimas de la desnutrición y de enfermedades curables; el escándalo de unas desigualdades socioeconómicas abismales y de un planeta al borde del colapso ecológico. Como saber ético, esta rama de la Ética ofrece un marco de referencia para revisar las teorías y las prácticas de quienes están involucrados en las tareas de cooperación al desarrollo (Kliksberg, 2002, 2005; Martínez Navarro, 2006), y al mismo tiempo constituye una denuncia académicamente rigurosa contra las injusticias que provoca la economía política vigente (Cortina, 2006; Conill, 2007; Jonjitud, 2007; Martínez Navarro, 2007). La denuncia bien fundamentada y la cooperación ajustada a valores éticos han de ir a la par, porque de lo contrario no será posible avanzar hacia un mundo más justo con un medio ambiente sano. 
La Ética del Desarrollo pretende orientar razonablemente el comportamiento de todas las personas, porque todos tenemos cierto grado de responsabilidad en que nuestro mundo adopte un patrón de desarrollo que no se convierta en maldesarrollo (Tortosa, 2011). Para ello cuenta con los instrumentos habituales de la Filosofía Moral y de las Éticas Aplicadas: argumentos, distinciones conceptuales y apelación a principios éticos previamente fundamentados en la racionalidad humana (Martínez Navarro, 2000; Gasper, 2004).

Por otro lado, es preciso subrayar que muchos de los objetivos que desde sus inicios (Goulet, 1965; Pablo VI, 1967) han sido señalados por la Ética del Desarrollo como objetivos éticos, vienen siendo asumidos por las Naciones Unidas en los últimos veinte años: tanto los Objetivos de Desarrollo del Milenio (ONU, 2000) como los Objetivos de Desarrollo Sostenible (ONU, 2015) han recogido en gran medida las exigencias de una ética universalista del desarrollo, teniendo en cuenta el escenario global y también los escenarios locales, especialmente en lo que se refiere a los países identificados como "menos adelantados" (Países Menos Adelantados: PMA), es decir, los más empobrecidos y atrasados (Sanahuja, 2014, 2015). En efecto, los Objetivos de Desarrollo Sostenible propuestos por la ONU en 2015 con un horizonte de cumplimiento establecido en 2030 -17 objetivos y 169 metas, la mayoría de ellos ligados a indicadores y plazos concretos- son congruentes con las orientaciones éticas que se han ido formulando como básicas y prioritarias en la ética del desarrollo. Es evidente que las exigencias que se derivan de la necesidad de detener el cambio climático constituyen un incentivo de gran urgencia, que obliga a la comunidad internacional a tomar en serio los imperativos de sostenibilidad medioambiental, y que tales imperativos están conectados, en la práctica, con ciertos imperativos de desarrollo humano (por ejemplo, no es posible detener el deterioro de las zonas boscosas sin atender simultáneamente las necesidades de desarrollo humano de las comunidades pobres que malviven en los territorios que habitan en tales zonas).

La ética del desarrollo como ética aplicada tiene todavía un amplio horizonte de actividad en cuestiones como el debate en torno a la desigualdad entre países y en el interior de cada país, la utilización de las tecnologías que resultan dañinas para las personas y/o para el medio ambiente, la preservación de los rasgos culturales que merezcan ser preservados (y la consecuente eliminación de otros rasgos culturales que pueden ser considerados como contrarios a la ética), etc. Por todo ello, considero que es preciso mantener y estimular la formación ética en este ámbito, con el compromiso de hacer llegar los argumentos y los principios éticos a todos los actores del desarrollo: gobiernos, organismos internacionales, empre- 
sas, organizaciones solidarias (ONG) y sobre todo a la juventud y a la ciudadanía en general, tanto en los países "desarrollados" (en los que sigue habiendo sectores marginados y maldesarrollo) como también en los países que ahora son llamados "en desarrollo". Mientras exista una sola comunidad en el mundo que no disfruta de todos los derechos humanos, la ética del desarrollo tendrá algo que decir al respecto, tanto para denunciar las injusticias como para "ayudar" solidariamente a las personas que están sufriendo tales injusticias.

\section{REFERENCIAS}

-Comisión mundial para el medio ambiente y el desarrollo (1988). Nuestro futuro común. Madrid: Alianza.

-Conill, J. \& Crocker, D. (Eds.) (2003). Republicanismo y educación cívica ¿̇ás allá del liberalismo? Granada: Comares.

-Conill, J. (2004). Horizontes de economía ética. Aristóteles, Adam Smith y Amartya Sen. Madrid: Tecnos.

-Conill, J. (2007). Ética universal de la cooperación y el desarrollo solidario. En J. Jongitud (Ed.), pp. 27-44.

-Cortina, A. (2006). Ética del desarrollo: un camino hacia la paz. Sistema, 192, 318.

-Cortina, A. \& Martínez, E. (1996). Ética. Madrid: Akal.

-Crocker, D. (2003). Globalización y desarrollo humano: Aproximaciones éticas. En J. Conill y D. Crocker (Eds.), Republicanismo y educación cívica ¿Más allá del liberalismo? (pp. 75-98). Granada: Comares.

-Crocker, D. (2007). Ética internacional del desarrollo: fuentes, acuerdos, controversias y agenda. Diálogo Filosófico, (69), 389-399.

-Galtung, J. (1978). The New International Order and the Basic Needs Approach. Alternatives, 4(9), 455-76.

-García Delgado, D. \& Molina, M. G. (2006). Ética y desarrollo. El conflicto de las interpretaciones. En J. C. Scannone y D. García Delgado (Comps.), (pp. 51-116).

-Gasper, D. (2004). The Ethics of Development From Economicism to Human Development. Edingburg: Edingburg University Press.

-Goulet, D. (1965). Ética del Desarrollo. Montevideo-Barcelona: Estela-IEPAL.

-Goulet, D. (1995a). Authentic development: is it sustainable? En T. Trzyna (Ed.), Defining and Measuring Sustainable Development (pp. 44-59). International Center for the Environment and Public Policy \& California Institute of Public Affairs for IUCN - the World Conservation Union.

-Goulet, D. (1995b). Development Ethics: A guide to theory and practice. New York: The Apex Press, London: Zed Books. [Hay trad. cast. (1999), Ética del desarrollo. Madrid: IEPALA]. 
-Griffin, K. (2001). Desarrollo humano: origen, evolución e impacto. En P. Ibarra y K. Unceta (Coords.), Ensayos sobre el desarrollo bumano (pp. 25-40). Barcelona: Icaria.

-Jonjitud, J. (Ed.) (2007). Ética del desarrollo y responsabilidad social en el contexto global. México: Universidad Veracruzana.

-Kliksberg, B. (Ed.) (2002). Ética y desarrollo. La relación marginada. Buenos Aires: $\mathrm{El}$ Ateneo.

-Kliksberg, B. (Ed.) (2005). La agenda ética pendiente de América Latina. Buenos Aires: Fondo de Cultura Económica / Banco Interamericano de Desarrollo.

-López, I. \& Alcalde, A. R. (Coords.) (1999). Relaciones de género y desarrollo. Hacia la equidad de la cooperación. Madrid: Instituto Universitario de Desarrollo y Cooperación / Los libros de la Catarata.

-Mangi, F. (2000). La despolitización de la pobreza. En F. Mangi y otros, Desarrollo y derechos humanos (pp. 12-34). Barcelona: Intermón.

-Martínez Navarro, E. (2000). Ética para el desarrollo de los pueblos. Madrid: Trotta.

-Martínez Navarro, E. (2006). Denuncia y cooperación: la ética de las organizaciones solidarias para el desarrollo. En Cuadernos Contraste, Murcia: Foro Ignacio Ellacuría. Disponible en http://www.foroellacuria.org/publicaciones.htm.

-Martínez Navarro, E. (2007). Ética para el desarrollo de los pueblos: panorámica y perspectivas. Diálogo Filosófico, (69), 362-388.

-Max-Neef, M. (1993). Human Scale Development: Conception, Application, and Further Reflections. London: Apex Press.

-Mealla, E. (2006). El regreso del desarrollo. En J. C. Scannone y D. García Delgado (Comps.), pp. 117-141.

-ONU (2015): Transformar nuestro mundo: la Agenda 2030 para el Desarrollo Sostenible. Resolución de la Asamblea General aprobada por la Asamblea General el 25 de septiembre de 2015. Recuperado de http://www.un.org/es/comun/docs/?symbol=A/RES/70/1

-Pablo VI (1967). Carta encíclica Populorum progressio. Recuperado de http://www.vatican.va/holy_father/paul_vi/encyclicals/documents/hf_pvi_enc_26031967_populorum_sp.html

-PNUD (1990 y siguientes). Informe sobre el desarrollo bumano. Recuperado de http://www.undp.org/content/undp/es/home/librarypage.html

-Pogge, T. (2002). World Poverty and Human Rights. Oxford: Polity Press / Blackwell. [Hay trad. cast. (2005), La pobreza en el mundo y los derechos humanos. Barcelona: Paidós].

-Riechmann, J. (1995). Desarrollo sostenible: la lucha por la interpretación. En J. Riechmann y otros, De la economía a la ecología (pp. 11-36). Madrid: Trotta/ Fundación $1^{\circ}$ de Mayo.

-Román, B. \& De Castro, G. (Eds.) (2013). Cambio social y cooperación en el siglo XXI (Vol.2, El reto de la equidad dentro de los límites ecológicos). Barcelona: Educo / Icaria Editorial. Disponible en http://www.intervida.org/es/publicaciones/estudios/nuevo-libro-de-educo-y-la-ub-sobre-cambio-social-y-cooperacion]. 
-Sanahuja, J. A. (2014). De los Objetivos del Milenio al desarrollo sostenible: Naciones Unidas y las metas globales post-2015. En M. Mesa (Coord.), Focos de tensión, cambio geopolítico y agenda global. Anuario 2014-2015 (pp. 49-83). Madrid: CEIPAZ.

-Sanahuja, J. A. (2015). La Agenda 2030 y los Objetivos de Desarrollo Sostenible: hacia una ética universalista del desarrollo global. Razón y Fe, 272(1405), 367381.

-Scannone, J. C. \& García Delgado, D. (Comps.) (2006). Ética, desarrollo y región. Hacia un regionalismo integral. Buenos Aires: Fundación Centro Integral Comunicación, Cultura y Sociedad CICCUS.

-Schweickart, D. (2002). After capitalism. Lanham: Rowman and Littlefield.

-Sen, A. (1999). Development as freedom. New York: Ramdom House. [Hay trad. cast. (2000), Desarrollo y libertad. Barcelona: Planeta].

-Singer, P. (1979). Practical Ethics. Cambridge: Cambridge University Press. [Hay trad. cast. (1984), Ética práctica. Barcelona: Ariel].

-Streeten, P. y otros (1981). First Things First: Meeting Basic Needs in Developing Countries. London: Oxford University Press. [Hay trad. cast. (1986), Lo primero es lo primero: satisfacer las necesidades básicas en los países en desarrollo. Madrid: Tecnos/Banco Mundial].

-Tortosa, J. M. (2011). Maldesarrollo y Mal Vivir: Pobrezay Violencia a Escala Mundial. Quito: Ediciones Abya-Yala. Recuperado de http://www.rosalux.org.ec/es/serie-nuevo-constitucionalismo/209-maldesarrollo.html

Sumario: 1. ¿En qué consiste la ética del desarrollo?; 2. ¿En qué consiste un desarrollo ético?; 3. ¿'Tenemos la obligación ética de ayudar a quienes padecen el subdesarrollo?; 4. Necesidades básicas y sostenibilidad medioambiental; 5. El desarrollo humano como clave ética del desarrollo; 6. ¿Qué nos aporta la Ética del Desarrollo?; Referencias. 